\title{
STRATEGI HIDUP PETANI PADI SAWAH DI DESA TUMANI SELATAN KECAMATAN MAESAAN KABUPATEN MINAHASA SELATAN
}

\author{
Glandie Runturambi \\ Elsje Pauline Manginsela \\ Olly Esry Harryani Laoh
}

\begin{abstract}
This study aims to determine the life strategy of wetland rice farmers in Tumani Selatan Village, Sub-District of Maesaan, South Minahsa Regency. This research was conducted for three months from September to November 2018. The data used in this study were primary and secondary data. Primary data collection through direct interviews with 15 respondents of paddy rice farmers based on a questionnaire that had been prepared previously. Secondary data was collected from the office of Desa Tumani Selatan, from the internet through google searching regarding the profile of South Minahasa Regency, and from previous research documents that were relevant to this study. Data analysis in this study is quantitative and qualitative analysis which is presented in the form of a table, then described descriptively. The results of the research that have been done show that the life strategy of the upper class of farmers applies two strategies, namely the accumulation strategy and consolidation strategy. Middle class farmers apply accumulation strategies. While the lower class farmers implement a survival strategy." ${ }^{* p r m *}$
\end{abstract}

Keywords: life strategy, wetland rice farmers, Tumani Selatan Village, South Minahasa Regency

\begin{abstract}
ABSTRAK
Penelitian ini bertujuan untuk mengetahui strategi hidup petani padi sawah di Desa Tumani Selatan Kecamatan Maesaan Kabupaten Minahsa Selatan. Penelitian ini dilaksanakan selama tiga bulan dari bulan September sampai dengan November 2018. Data yang digunakan pada penelitian ini adalah data primer dan sekunder. Pengumpulan data primer melalui wawancara langsung kepada 15 responden petani padi sawah berdasarkan kuesioner yang telah disusun sebelumnya. Data sekunder dikumpulkan dari kantor Desa Tumani Selatan, dari internet melalui google searching menyangkut profil Kabupaten Minahasa Selatan, dan dari dokumen penelitian sebelumnya yang relevan dengan penelitian ini. Analisis data dalam penelitian ini adalah analisis kuantitatif dan kualitatif yang disajikan dalam bentuk table, kemudian dijabarkan secara deskriptif. Hasil penelitian yang telah di lakukan menunjukkan bahwa strategi hidup petani lapisan atas menerapkan dua strategi, yaitu strategi akumulasi dan strategi konsolidasi. Petani lapisan menengah menerapkan strategi akumulasi. Sedangkan petani lapisan bawah menerapkan strategi bertahan hidup. *epm*
\end{abstract}

Kata kunci : strategi hidup, petani padi sawah, Desa Tumani Selatan, Kabupaten Minahasa Selatan

\section{PENDAHULUAN}

\section{Latar Belakang}

Indonesia merupakan negara agraris dengan lahan pertanian yang luas dimana sebagian besar pendudukya berprofesi sebagai petani. Negara ini diuntungkan karena dikaruniai kondisi alam yang mendukung yaitu hamparan lahan yang luas, keragaman hayati yang melimpah, serta beriklim tropis dimana sinar matahari terjadi sepanjang tahun sehingga dapat menanam sepanjang tahun. 
Pertanian merupakan mata pencaharian pokok sebagian besar masyarakat di perdesaan. Dalam dunia pertanian, manusia dan tanah merupakan sumber daya yang berkaitan erat, karena tanah merupakan tempat berpijak manusia dan tempat manusia untuk mengolah tanaman pertaniannya demi kelangsungan hidupnya (Mardikantoro, 2013).

Pekerjaan sebagai petani merupakan salah satu alternatif untuk dapat melangsungkan kehidupan masyarakat desa. Pekerjaan ini dapat dilakukan oleh siapa saja tanpa memerlukan pengetahuan yang tinggi karena dapat hanya mengandalkan tenaga. Pada masyarakat tani dapat di bedakan menjadi beberapa lapisan berdasarkan, antara lain, keberhasilan dalam mengelola usahataninya, pemilikan lahan dan modal. Bagi sebagian petani yang belum berhasil terasa berat beban mereka karena mereka harus mencukupi bermacam-macam kebutuhan hidupnya. Dengan keterbatasan penghasilan mereka berupaya untuk menyekolahkan anak dan mencukupkan kebutuhan keluarga berupa makan, minum dan pakaian (Khairani, 2010).

Seperti yang dikemukakan Scott (1989) bahwa dengan kebutuhan hidup yang semakin meningkat mendorong petani untuk berperilaku sebagai petani survival demi memenuhi kebutuhannya. Maka masalah yang dihadapi petani adalah bagaimana menghasilkan pendapatan yang cukup untuk memenuhi kebutuhan makan sekeluarga dan untuk membeli barang kebutuhan lainnya dalam (Sugihardjo, 2012)

Dalam pertanian, status petani dapat dikelompokan menjadi tiga yaitu petani pemilik, petani penggarap dan buruh tani. Dari pembagian ini, mereka mempunyai fungsi dan peranan masingmasing. Dalam hubungan antara pemilik lahan dan tenega kerja pertanian terdapat sistem bawon, upah harian, upah borongan, upah bulanan dan minggguan.

Kabupaten Minahasa Selatan merupakan salah satu daerah di mana sektor pertanian menjadi sumber mata pencarian bagi sebagian masyarakatnya. Menurut data dari Badan Pusat Statistik, mengukur lahan pertanian Indonesia pada tahun 2018, luas lahan persawahan di Kabupaten Minahasa Selatan yaitu seluas 5,491.00 Ha. Dari luas lahan persawahan tersebut dapat dikatakan bahwa bertani merupakan pekerjaan yang banyak dilakukan oleh masyarakatnya. Dilihat dari luas lahan pertanian berdasarkan Kecamatan di kabupaten ini salah satunya adalah Kecamatan Mesaaan yang mana Kecamatan ini memiliki luas lahan Pertanian Seluas 310.00 Ha. Tumani Selatan adalah salah satu Desa yang berada di Kabupatan
Minahasa Selatan tepatnya di Kecamatan Maesaan merupakan salah satu sentra produksi padi yang mana tanaman padi merupakan komoditi utama dengan luas lahan sawah $42.00 \mathrm{Ha}$.

Secara umum petani di daerah perdesaan, termasuk petani yang ada di Desa Tumani Selatan, dapat dibedakan antara lain berdasarkan luas lahan dan kondisi rumah. Untuk itu petani di perdesaan terdiri atas petani lapisan atas, petani lapisan menengah dan petani lapisan bawah. Menurut Breman (1992), setiap lapisan memiliki strategi hidup/nafkah yang berbeda lapisan atas menerapkan strategi akumulasi, lapisan menengah menerapkan strategi konsolidasi dan lapisan bawah menerapkan strategi bertahan hidup. Namun ada juga mereka yang bekerja bukan sebagai petani karena bekerja di non-pertanian untuk memenuhi kebutuhan hidup keluarganya. Antara lain sebagai Pegawai Negeri Sipil, buruh bangunan, penambang, tukang ojek, sopir, dan peternak sapi, babi, dan ayam.

\section{Rumusan Masalah}

Berdasarkan latar belakang maka perumusan masalah dalam penelitian ini adalah bagaimana Strategi Hidup Petani Padi sawah di Desa Tumani Selatan Kecamatan Maesaan Kabupaten Minahasa Selatan untuk melangsungkan kehidupan keluarga baik sebagai petani lapisan atas, petani lapisan menengah dan petani lapisan bawah?

\section{Tujuan Penelitian.}

Mengetahui Strategi Hidup Petani Padi sawah di Desa Tumani Selatan Kecamatan Maesaan Kabupaten Minahasa Selatan baik petani lapisan atas, petani lapisan menengah dan petani lapisan bawah untuk membiayai kebutuhan hidup keluarganya sehari-hari. Baik bekerja sebagai petani maupun pekerjaan tambahan di luar pekerjaan sebagai petani.

\section{Manfaat Penelitian}

Penelitian ini diharapkan dapat bermanfaat bagi:

1. Penulis

Selain untuk penyelesaian studi akhir, juga dapat meningkatkan pengetahuan tentang strategi hidup petani padi sawah.

2. Masyarakat

Memberikan informasi bagi pihak-pihak yang memerlukan serta menambahkan wawasan yang lebih luas mengenai strategi hidup petani padi sawah di Desa Tumani Selatan Kecamatan Maesaan Kabupaten Minahasa Selatan. 


\section{METODE PENELITIAN}

\section{Waktu dan Tempat Penelitian}

Penelitian ini di lakukan di Desa Tumani Selatan Kecamatan Maesaan Kabupaten Minahasa Selatan. Penelitian ini di laksanakan pada Bulan September sampai Bulan November 2018.

\section{Metode Pengumpulan Data}

Penelitian ini menggunakan data primer dan data sekunder. Data primer diperoleh dari wawancara langsung kepada 15 responden petani padi sawah. Pengumpulan data dalam penelitian ini adalah secara sengaja (purposive sampling) dimana yang menjadi sampel adalah petani padi sawah pemilik penggarap dan penggarap, sedangkan data sekunder di peroleh dari kantor pemerintah Desa Tumani Selatan dan instansi terkait.

\section{Konsep dan Pengukuran Variabel}

1. Karakteristik Responden
a. Umur Responden
b. Tingkat pendidikan, yaitu dilihat dari pendidikan terakhir responden
c. Luas lahan Responden
d. Status Petani
e. Kondisi Rumah Petani

2. Tiga Lapisan Masyarakat

a. Lapisan Atas yaitu, petani pemilik atau penggarap lahan pertanian lebih dari 1 ha., pedagang dan pemilik toko, pegawai pimpinan dan guru.

b. Lapisan Menengah yaitu, petani pemilik atau penyewa lahan pertanian 0,75 sampai 1 ha., pedagang dengan modal kecil, pemilik warung, penarik ojek, tukang ahli dan buruh dengan pekerjaan tetap, pegawai rendah (seperti hansip dan penjaga pintu air);

c. Lapisan Bawah yaitu. buruh tani, pemilik dan penyewa lahan marginal, pekerja kasar dan pekerja tidak tetap, pekerja transport tanpa milik, pedagang asongan dan pembantu rumah tangga.

3. Strategi hidup petani yang merupakan cara hidup untuk memenuhi kebutuhan keluarga:

a. Strategi akumulasi, yaitu petani mengumpulkan harta mereka sehingga semakin hari semakin bertambah baik dalam tanah pertanian ataupun usaha di luar bertani.

b. Strategi konsolidasi, yaitu petani yang mempunyai lahan yang berjauhan lokasi. Salah satu lahan dijual untuk membeli lahan yang berdekatan lokasinya sehingga menjadi satu hamparan yang lebih luas agar lebih mudah di jangkau dan dikelola.

c. Strategi bertahan hidup, yaitu petani mengurangi pengeluaran untuk pangan, menggunakan alternatif subsistem dan meminta bantuan dari jaringan sosial pada saat mengalami kekurangan.

1. Sandang, yaitu berapa kali mereka membeli pakaian dalam setahun.

2. Pangan, mereka makan sehari-hari, berapa kali dalam satu hari.

3. Papan, mereka menempati rumah tinggal sekarang, sewa, beli atau milik sendiri.

4. Pendidikan anak: menyekolahkan anak sampai di tingkat apa.

5. Kesehatan, yaitu bila sakit berobat ke Puskesmas, Rumah Sakit, Klinik, beli obat di apotik atau beli obat di warung. Biayanya menggunakan BPJS, atau Dana sehat, dan sebagainya.

6. Pendapatan rumah tangga (Rp/bulan) adalah pendapatan yang diperoleh dari hasil bertani dan pendapatan ( $\mathrm{Rp} /$ bulan) dari sumber-sumber lain dari anggota keluarga.

7. Pengeluaran untuk makan (Rp/bulan)

8. Cara mengelola lahan pertaniannya antara lain dengan mengerjakan sendiri atau menyewa pekerja tani dalam usaha pertanian.

\section{Analisis Data}

Sugiyono (2009), analisis data merupakan proses mencari dan menyusun secara sistematis data yang diperoleh dari hasil angket, catatan lapangan, dan bahan-bahan lain sehingga dapat mudah dipahami dan temuannya dapat diinformasikan kepada orang lain. Analisis data dalam penelitian ini adalah data yang diperoleh dari wawancara yang disajikan dalam bentuk tabel maupun diagram yang kemudian dianalisisis secara kuantitatif, kemudian dijabarkan secara deskriptif. 


\section{HASIL DAN PEMBAHASAN}

\section{Deskripsi Wilayah Penelitian}

Desa Tumani Selatan merupakan Desa yang terletak di Kecamatan Maesaan, Kabupaten Minahasa Selatan, Provinsi Sulawesi Utara. Terdiri dari 4 jaga/dusun. Dengan batas geografis wilayah :

Sebelah Utara : Desa Tumani

Sebelah Timur : Desa Kinalawiran

Sebelah Barat : Desa Lowian

Sebelah Selatan : Desa Kinaweruan

Wilayah ini berada pada ketinggian 800 meter di atas permukaan laut sehingga cocok untuk tanaman pertanian. Desa Tumani Selatan memiliki 232 keluarga, dan jumlah penduduk 708 orang dengan luas wilayah $145 \mathrm{Ha}$.

\section{Karakteristik Responden}

Karakteristik responden dalam penelitian ini antara lain:

\section{Umur Responden}

Pada Tabel 1, umur responden petani lapisan atas berkisar antara 44-72 tahun. Sedangkan umur responden petani lapisan menengah antara 46-66 tahun. Dan umur responden petani lapisan bawah berkisar 45-78 tahun. Sebagian besar responden berada di kelompok umur yang masih produktif yang mana pada kelompok umur ini petani masih mempunyai tenaga yang cukup kuat dalam berusahatani padi sawah. Lama mereka berprofesi sebagai petani antara 18 tahun sampai 60an tahun lamanya dan usia mereka mulai menjalankan profesi sebagai petani rata-rata di usia mereka yang masih remaja.

\begin{tabular}{lcr} 
Tabel 1. Kelompok Umur Petani & \\
\hline Kelompok Umur & Jumlah Petani & Persentase (\%) \\
\hline Petani Lapisan Atas & & 75 \\
\hline$<51$ tahun & 3 & - \\
$51-59$ tahun & - & 25 \\
59> tahun & 1 & 100 \\
\hline Sub-Jumlah & 4 & \\
\hline Petani Lapisan Menengah & & 66.6 \\
\hline$<51$ tahun & 4 & - \\
$51-59$ tahun & - & 33.4 \\
59> tahun & 2 & 100 \\
\hline Sub-Jumlah & 6 & \\
\hline Petani Lapisan Bawah & & 40 \\
\hline$<51$ tahun & 2 & 60 \\
\hline $51-59$ tahun & - & 100 \\
\hline $59>$ tahun & 3 & 100 \\
\hline Sub-Jumlah & 5 & \\
\hline Jumlah Total & 15 & \\
\hline Sumber : Diolah dari data primer, 2018 &
\end{tabular}

\section{Pendidikan Petani}

Pendidikan responden pada penelitian ini terdiri dari Sekolah Dasar, Sekolah Menengah Pertama, Sekolah Menengah Atas Dan Sarjana. Pendidikan terakhir petani lapisan atas tergolong tinggi karena, dari 4 responden kepala keluarga dan ibu rumah tangga berlatar belakang pendidikan SMP, SMA sampai S1 dan hanya ada 1 kepala keluarga dan ibu rumah tangga yang berlatar belakang pendidikan SD. Sedangkan pendidikan terakhir petani lapisan menengah dari 6 responden terdapat 3 kepala keluarga berlatar belakang pendidikan SMA, 1 kepala keluarga tingkat SMP dan 2 kepala keluarga tingkat SD dan untuk ibu rumah tangga 1 pendidikan S1, 1 pendidikan SMA, 3 pendidikan tingkat SMP dan 1 tingkat SD. Dan petani lapisan bawah dari 5 responden hanya 1 kepala keluarga yang berlatar belakang pendidikan SMA, 1 kepala keluarga tingkat SMP dan 2 tingkat SD. Semakin tinggi tingkat pendidikan seseorang semakin banyak pula pengetahuan atau wawasan yang dimiliki, baik itu menciptakan, menerapkan teknologi baru serta inovasi-inovasi yang baru. Selain itu semakin tinggi tingkat pendidikan seseorang semakin dewasa dalam bertindak dan mudah memahami setiap persoalan yang dihadapinya.

\begin{tabular}{llll} 
Tabel 2. & $\begin{array}{l}\text { Pendidikan Petani Kepala Keluarga dan Ibu Rumah Tangga } \\
\text { Berdasarkan Pendidikan Terakhir }\end{array}$ \\
& $\begin{array}{l}\text { Petani } \\
\text { Lapisan } \\
\text { Atas }\end{array}$ & $\begin{array}{l}\text { Petani Lapisan } \\
\text { Menengah }\end{array}$ & $\begin{array}{l}\text { Petani } \\
\text { Bawah }\end{array}$ \\
\hline & & & \\
\hline Kepala Keluarga & 2 & 3 & 1 \\
\hline SMA & 1 & 1 & 2 \\
SMP & 1 & 2 & 2 \\
SD & 4 & 6 & 5 \\
\hline Jumlah & & & \\
\hline Ibu Rumah Tangga & 1 & 1 & 1 \\
\hline Strata 1 & 1 & 1 & 3 \\
SMA & 1 & 3 & 1 \\
SMP & 1 & 1 & 5 \\
SD & 4 & 6 & \\
\hline Jumlah & & &
\end{tabular}

Sumber : Diolah dari data primer, 2018

\section{Luas Lahan Petani Padi Sawah di Desa Tumani Selatan}

Tabel 3 menunjukkan luas lahan petani lapisan atas yang terdiri dari 4 responden berjumlah 10,7 ha, petani lapisan menengah terdiri dari 6 responden dengan jumlah luas lahan 5,2 ha, dan petani lapisan bawah dengan 5 responden memiliki jumlah luas lahan 2,3 ha. Jadi total seluruh luas lahan petani lapisan atas, menengah dan bawah berjumlah 18,25 ha. Semakin tinggi lapisan petani semakin luas lahan yang dimiliki petani. Namun rata-rata luas lahan yang dimiliki petani masih dibawah 1,25 ha 


\begin{tabular}{lrr}
\multicolumn{2}{l}{ Tabel 3. Luas Lahan Petani Padi Sawah } & \\
\hline Keterangan & Responden & Luas Lahan (Ha) \\
\hline Petani Lapisan Atas & 1 & 4 \\
& 2 & 3 \\
& 3 & 2 \\
& 4 & 1,7 \\
\hline Rata-rata & & 2,68 \\
\hline Sub jumlah & 4 & 10,7 \\
\hline Petani Lapisan Menengah & 1 & 1 \\
& 2 & 1 \\
& 3 & 1 \\
& 4 & 0,75 \\
& 5 & 0,75 \\
& 6 & 0,75 \\
\hline Rata-rata & & 0,88 \\
\hline Sub jumlah & 6 & 5,25 \\
\hline Petani Lapisan Bawah & 1 & 0.7 \\
\hline & 2 & 0,7 \\
& 3 & 0,7 \\
& 4 & 0,5 \\
& 5 & 0,4 \\
\hline Rata-rata & & 0,46 \\
\hline Sub jumlah & 2 & 1,3 \\
\hline Total rata-rata & & 18,25 \\
\hline Jumlah & & \\
\hline Sumber : Diolah dari data primer, 2018 & & \\
& &
\end{tabular}

\section{Pendapatan Usahatani Padi Sawah dan di} Luar Usahatani Padi Sawah Perbulan

Pendapatan petani lapisan atas yaitu terdiri dari pendapatan usahatani padi sawah sebesar Rp. 1.250.000 sampai Rp. 7.500.000 terdiri dari 4 petani sehingga menjadi rata-rata pendapatan petani lapisan atas Rp. 3.890 .625 perbulan dan untuk pendapatan di luar usahatani padi sawah Rp. 3.000.000 sampai Rp. 11.000 .000 terdiri dari 2 petani sehingga menjadi rata-rata pendapatan Rp. 3.500.000 perbulan sehingga di rata-ratakan semua jumlah pendapatan petani lapisan atas perbulan perpetani sebesar Rp. 7.390.625.

Pendapatan usahatani padi sawah petani lapisan menengah yaitu Rp. 750.000 sampai Rp. 2.500.000 terdiri dari 6 petani dan rata-rata pendapatan petani lapisan Menengah $\mathrm{Rp}$. 1.635.417 perbulan dan untuk pendapatan di luar usahatani padi sawah yaitu Rp. 300.000 sampai Rp. 3.200 .000 terdiri dari 6 petani dan rata-rata pendapatan di luar usahatani padi sawah $\mathrm{Rp}$. 1.958.333 perbulan. Sehingga di rata-ratakan semua jumlah pendapatan petani lapisan menengah sebesar Rp. 3.593 .750 perbulan perpetani.

Pendapatan usahatani padi sawah petani lapisan bawah yaitu Rp. 375.000 sampai $\mathrm{Rp}$. 1.000.000 terdiri dari 5 petani dan rata-rata pendapatan petani lapisan bawah Rp. 7.000.000 perbulan dan untuk pendapatan di luar usahatani padi sawah yaitu Rp. 200.000 sampai Rp. 2.016.000 terdiri dari 5 petani dan rata-rata pendapatan petani lapisan bawah Rp. 1.393 .200 perbulan. Sehingga di rata-ratakan semua jumlah pendapatan petani lapisan bawah sebesar Rp. 2.093.200 perbulan perpetani.

\begin{tabular}{|c|c|c|c|c|c|c|}
\hline \multirow{2}{*}{ Keterangan } & \multirow[b]{2}{*}{ No } & \multicolumn{2}{|l|}{ Petani } & \multirow{2}{*}{$\begin{array}{c}\text { Petani } \\
\text { lapisan } \\
\text { menengah }\end{array}$} & \multirow[b]{2}{*}{ No } & \multirow{2}{*}{$\begin{array}{c}\text { Petani } \\
\text { lapisan bawah }\end{array}$} \\
\hline & & lapisan atas & No & & & \\
\hline \multirow{6}{*}{$\begin{array}{l}\text { Usahatanı } \\
\text { Padi Sawah }\end{array}$} & 1 & 7.500 .000 & 1 & 2.500 .000 & 1 & 1.000 .000 \\
\hline & 2 & 1.250 .000 & 2 & 2.500 .000 & 2 & 750.000 \\
\hline & 3 & 1.812 .500 & 3 & 2.062 .500 & 3 & 750.000 \\
\hline & 4 & 5.000 .000 & 4 & 1.125 .000 & 4 & 375.000 \\
\hline & & & 5 & 750.000 & 5 & 625.000 \\
\hline & & & 6 & 875.000 & & \\
\hline Rata- rata (Rp) & & 3.890 .625 & & 1.635 .417 & & 700.000 \\
\hline \multirow{6}{*}{$\begin{array}{l}\text { Non Usahatani Padi } \\
\text { Sawah }\end{array}$} & 1 & 0 & 1 & 2.000 .000 & 1 & 0 \\
\hline & 2 & 3.000 .000 & 2 & 2.000 .000 & 2 & 200.000 \\
\hline & 3 & 0 & 3 & 3.200 .000 & 3 & 1.750 .000 \\
\hline & 4 & 11.000 .000 & 4 & 1.950 .000 & 4 & 3.000 .000 \\
\hline & & & 5 & 2.300 .000 & 5 & 2.016 .000 \\
\hline & & & 6 & 300.000 & & \\
\hline Rata- rata (Rp) & & 3.500 .000 & & 1.958 .333 & & 1.393 .200 \\
\hline \multirow[t]{6}{*}{ Total pendapatan } & 1 & 7.500 .000 & 1 & 4.500 .000 & 1 & 1.000 .000 \\
\hline & 2 & 4.250 .000 & 2 & 4.500 .000 & 2 & 950.000 \\
\hline & 3 & 1.812 .500 & 3 & 5.262 .500 & 3 & 2.500 .000 \\
\hline & 4 & 16.000 .000 & 4 & 3.075 .000 & 4 & 3.375 .000 \\
\hline & & & 5 & 3.050 .000 & 5 & 2.641 .000 \\
\hline & & & 6 & 1.175 .000 & & \\
\hline Rata- rata (Rp) & & 7.390 .625 & & 3.593 .750 & & 2.093 .200 \\
\hline
\end{tabular}

Tabel 4 menunjukkan bahwa pendapatan petani lapisan atas lebih tinggi di bandingkan petani lapisan menengah dan bawah petani lapisan bawah memiliki pendapatan yang lebih kecil dari petani lapisan menengah. Pada tabel 5 menunjukkan petani lapisan bawah tidak cukup memenuhi kebutuhan kelangsungan hidup keluarga perbulan.

\section{Pengeluaran Makan, Non Makan Dan Sisa Uang Petani Perbulan}

Pengeluaran petani padi sawah perbulan adalah pengeluaran makan dan non makan. Pengeluaran makan adalah pengeluaran untuk membeli lauk pauk, sayur-sayuran, beras, bumbu dapur, minyak dan gas. Pengeluaran non makan petani padi sawah berupa biaya listrik perbulan, tv kabel perbulan, air pam perbulan, spp anak petani yang kuliah dan jajan anak sekolah.

Tabel 5 menunjukkan pengeluaran makan, non makan, dan sisa uang petani perbulan. Pengeluaran makan petani lapisan atas yang terdiri dari 4 responden dengan rata-rata Rp. 1.625.000 sedangkan pengeluaran non makan petani lapisan atas rata-rata Rp. 1.621.000 dan sisa uang petani padi sawah perbulan rata-rata Rp. 4.145.625.

Pengeluaran makan petani lapisan menengah yang terdiri dari 6 responden dengan rata-rata $\mathrm{Rp}$. 1.425.000 sedangkan pengeluaran non makan petani lapisan menengah rata-rata Rp. 794.643 dan sisa uang petani lapisan menengah perbulan rata-rata $\mathrm{Rp}$. 1.479.167.

Pengeluaran makan petani lapisan bawah yang terdiri dari 5 responden dengan rata-rata $\mathrm{Rp}$. 1.680.000 sedangkan pengeluaran non makan petani lapisan menengah rata-rata Rp. 629.250 dan sisa uang petani lapisan menengah perbulan rata-rata $\mathrm{Rp}$. -5.900 . 
Tabel 5. Pengeluaran Makan, Non Makan, dan Sisa Uang Petani Perbulan

\begin{tabular}{|c|c|c|c|c|c|c|}
\hline Keterangan & No & $\begin{array}{c}\text { Petani } \\
\text { lapisan atas }\end{array}$ & No & $\begin{array}{c}\text { Petani lapisan } \\
\text { menengah }\end{array}$ & No & $\begin{array}{c}\text { Petani lapisan } \\
\text { bawah }\end{array}$ \\
\hline \multirow{6}{*}{$\begin{array}{l}\text { Pengeluaran } \\
\text { makan }\end{array}$} & 1 & 1.800 .000 & 1 & 1.500 .000 & 1 & 1.500 .000 \\
\hline & 2 & 1.100 .000 & 2 & 1.500 .000 & 2 & 1.500 .000 \\
\hline & 3 & 600.000 & 3 & 3.000 .000 & 3 & 1.500 .000 \\
\hline & 4 & 3.000 .000 & 4 & 1.050 .000 & 4 & 900.000 \\
\hline & & & 5 & 900.000 & 5 & 3.000 .000 \\
\hline & & & 6 & 600.000 & & \\
\hline $\begin{array}{l}\text { Rata- rata } \\
\text { (Rp) }\end{array}$ & & 1.625 .000 & & 1.425 .000 & & 1.680 .000 \\
\hline \multirow{6}{*}{$\begin{array}{l}\text { Pengeluaran } \\
\text { non makan }\end{array}$} & 1 & 855.000 & 1 & 1.060 .000 & 1 & 122.000 \\
\hline & 2 & 920.000 & 2 & 295.000 & 2 & 550.000 \\
\hline & 3 & 180.000 & 3 & 1.035 .000 & 3 & 632.500 \\
\hline & 4 & 4.525 .000 & 4 & 280.000 & 4 & 125.000 \\
\hline & & & 5 & 1.037 .500 & 5 & 666.000 \\
\hline & & & 6 & 430.000 & & \\
\hline $\begin{array}{l}\text { Rata- rata } \\
\text { (Rp) }\end{array}$ & & 1.621 .000 & & 794.643 & & 629.250 \\
\hline \multirow{6}{*}{$\begin{array}{l}\text { Total } \\
\text { pengeluaran }\end{array}$} & 1 & 2.655 .000 & 1 & 2.560 .000 & 1 & 1.622 .000 \\
\hline & 2 & 2.020 .000 & 2 & 1.795 .000 & 2 & 2.050 .000 \\
\hline & 3 & 780.000 & 3 & 4.035 .000 & 3 & 2.132 .500 \\
\hline & 4 & 7.525 .000 & 4 & 1.330 .000 & 4 & 1.025 .000 \\
\hline & & & 5 & 1.937 .500 & 5 & 3.666 .000 \\
\hline & & & 6 & 1.030 .000 & & \\
\hline $\begin{array}{l}\text { Rata- rata } \\
\text { (Rp) }\end{array}$ & & 3.245 .000 & & 2.114 .583 & & 2.099 .100 \\
\hline \multirow{6}{*}{$\begin{array}{l}\text { Sisa uang } \\
\text { perbulan }\end{array}$} & 1 & 4.845 .000 & 1 & 1.940 .000 & 1 & -622.000 \\
\hline & 2 & 2.230 .000 & 2 & 2.705 .000 & 2 & -1.100 .000 \\
\hline & 3 & 1.032 .500 & 3 & 1.227 .500 & 3 & 367.500 \\
\hline & 4 & 8.475 .000 & 4 & 1.745 .000 & 4 & 2.350 .000 \\
\hline & & & 5 & 1.112 .500 & 5 & -1.025 .000 \\
\hline & & & 6 & 145.000 & & \\
\hline Rata- rata (Rp) & & 4.145 .625 & & 1.479 .167 & & -5.900 \\
\hline
\end{tabular}

\section{Tenaga Kerja Dalam Keluarga Dan Tenaga Kerja di Luar Keluarga}

Tenaga kerja petani padi sawah dalam penelitian ini diperoleh dari dalam dan luar keluarga. Dari luar keluarga dengan cara menyewa pekerja untuk mengolah lahan, menanam dan pada saat panen dan pasca panen dan sedangkan tenaga kerja dalam keluarga dengan cara bekerja sendiri mengurus tananaman tersebut dibantu oleh anggota keluarga lainnya dengan tidak memberikan upah. Lihat Tabel 6.

Tabel 6. Penyewaan Tenaga Kerja Dalam Keluarga dan Tenaga Kerja Luar Keluarga

\begin{tabular}{lcr}
\hline Menyewa Tenaga Kerja & Jumlah Responden & Persentase (\%) \\
\hline Petani Lapisan Atas & & \\
\hline Tenaga Kerja Dalam Keluarga & 2 & 50 \\
Tenaga Kerja Luar Keluarga & 2 & 50 \\
\hline Sub-Jumlah & 4 & 100 \\
\hline Petani Lapisan Menengah & & 83.4 \\
\hline Tenaga Kerja Dalam Keluarga & 5 & 16.6 \\
Tenaga Kerja Luar Keluarga & 1 & 100 \\
\hline Sub-Jumlah & 6 & \\
\hline Petani Lapisan Bawah & & 80 \\
\hline Tenaga Kerja Dalam Keluarga & 4 & 100 \\
Tenaga Kerja Luar Keluarga & 1 & 100 \\
\hline Sub-Jumlah & 5 & \\
\hline Jumlah & 15 & \\
\hline Sumber : Diolah dari data primer, 2018 & &
\end{tabular}

\section{Kebutuhan Pangan}

Kebutuhan pangan adalah salah satu kebutuhan dasar petani yang harus terpenuhi. Pemenuhan kebutuhan pangan dan pola makan petani, berdasarkan pola makan petani pada Tabel 7 baik petani lapisan atas, petani lapisan menengah dan petani lapisan bawah tidak ada perbedaan pola makan sama-sama pola makan mereka dalam sehari 3 kali yaitu pada waktu pagi, siang dan malam.

Tabel 7. Pola makan keluarga petani

\begin{tabular}{lcc}
\hline Pola Makan & Jumlah & Persentase \% \\
\hline Petani Lapisan Atas & & \\
\hline 3X (Pagi-siang-malam) & 4 & 100 \\
2X (Pagi-sore) & - & \\
2X (Siang-malam) & - & 100 \\
\hline Sub-Jumlah & 4 & 100 \\
\hline Petani Lapisan Menengah & & \\
\hline 3X (Pagi-siang-malam) & 6 & 100 \\
2X (Pagi-sore) & - & \\
2X (Siang-malam) & - & \\
\hline Sub-Jumlah & 6 & \\
\hline Petani Lapisan Bawah & & 100 \\
\hline 3X (Pagi-siang-malam) & 5 & \\
2X (Pagi-sore) & - & \\
2X (Siang-malam) & 5 & \\
\hline Sub-Jumlah & 15 & \\
\hline Jumlah & & \\
\hline Sumber : Diolah dari data primer, 2018 & & \\
& & \\
\end{tabular}

\section{Kebutuhan Sandang}

Tabel 8 menunjukkan pembelian pakaian bagi para petani dan keluarganya dalam satu tahun. Untuk memenuhi kebutuhan sandang petani membeli pakaian satu sampai tiga kali dalam setahun, yaitu pakaian gereja dan pakaian santay pada saat Perayaan Natal, Pengucapan Syukur, dan pakaian untuk acara perayaan kemerdekaan RI.

Pada petani lapisan atas ada 2 keluarga petani yang membeli pakaian 3 kali dalam setahun yaitu pada perayaan hari natal, pengucapan syukur dan hari kemerdekaan RI untuk anak petani yang masih sekolah dan 2 keluarga petani membeli pakaian 2 kali dalam setahun yaitu pada hari natal dan pengucapan syukur. Petani lapisan menengah ada 2 keluarga petani yang membeli pakaian 3 kali dalam setahun yaitu pada perayaan hari natal dan, pengucapan syukur dan hari kemerdekaan RI. Dan 4 keluarga petani membeli pakaian 1 kali dalam setahun yaitu pada saat perayaan hari natal. Sedangkan pada petani lapisan bawah hanya 1 keluarga petani yang membeli pakaian 2 kali dalam setahun yaitu perayaan hari natal dan hari kemerdekaan RI. Dan 4 keluarga petani yang membeli pakaian 1 kali dalam setahun yaitu hanya pada saat perayaan hari natal. 


\section{Kebutuhan Papan}

Kebutuhan papan merupakan kebutuhan dasar yang harus di penuhi karena semua manusia butuh tempat tinggal agar bisa terlindungi dari hujan, panas terik, menjadi tempat beristirahat dan tempat berkumpul keluarga.

Tabel 8. Pembelian Pakaian Petani dan Keluarga Dalam Setahun

\begin{tabular}{ll}
\hline Pembelian Pakaian Dalam Setahun & Jumlah Responden \\
\hline Petani Lapisan Atas & \\
\hline Tiga kali & 2 \\
Dua Kali & 2 \\
Satu Kali & - \\
\hline Sub-Jumlah & \\
\hline Petani Lapisan Menengah & 2 \\
\hline Tiga kali & - \\
Dua Kali & 4 \\
Satu Kali & 6 \\
\hline Sub-Jumlah & \\
\hline Petani Lapisan Bawah & - \\
\hline Tiga kali & 1 \\
Dua Kali & 4 \\
Satu Kali & 5 \\
\hline Sub-Jumlah & 15 \\
\hline Jumlah &
\end{tabular}

Tabel 9 menunjukkan status rumah dan tanah milik petani dibeli atau diwariskan. Dari 15 responden baik petani lapisan atas, lapisan menengah dan petani lapisan bawah terdapat masing-masing 1 petani yang memperoleh rumah tempat tinggal dari warisan orang tua. Sedangkan 12 responden lainya membeli rumah tempat tinggal yaitu, 4 responden membeli rumah tempat tinggal dari hasil tambang dan 8 responden membeli rumah tempat tinggal dari hasil bertani.

\begin{tabular}{lcc} 
Tabel 9. Status Rumah Tempat Tinggal Dan Tanah Milik & \\
\hline Status Rumah Dan Tanah & Jumlah Responden & Persentase (\%) \\
\hline Petani Lapisan Atas & 3 & \\
\hline Milik Sendiri (dibeli) & 1 & 75 \\
Milik Sendiri (warisan) & - & 25 \\
Disewa & 4 & 100 \\
\hline Sub-Jumlah & & \\
\hline Petani Lapisan Menengah & 5 & 83.4 \\
\hline Milik Sendiri (dibeli) & 1 & 16.6 \\
Milik Sendiri (warisan) & - & \\
Disewa & 6 & 100 \\
\hline Sub-Jumlah & & 80 \\
\hline Petani Lapisan Bawah & 4 & 20 \\
\hline Milik Sendiri (dibeli) & 1 & 100 \\
Milik Sendiri (warisan) & - & 100 \\
Disewa & 5 & \\
\hline Sub-Jumlah & 15 & \\
\hline Jumlah & & \\
\hline Sumber : Diolah dari data primer, 2018 & & \\
& &
\end{tabular}

Tabel 10 menunjukkan jenis bengunan rumah tempat tinggal petani lapisan atas dari 4 responden terdapat 3 petani dengan jenis bangunan rumah permanen dan 1 petani jenis bangunan semi permanen, petani lapisan menengah dari 6 reponden terdapat 3 petani dengan jenis bangunan rumah permanen dan 3 petani jenis bangunan semi permanen dan untuk petani lapisan bawah terdiri dari 5 responden terdapat 2 petani dengan jenis bengunan rumah permanen dan 2 petani jenis bengunan rumah semi permanen.

\begin{tabular}{lcc} 
Tabel 10. Jenis Bangunan Rumah Tempat Tinggal Petani & \\
\hline Jenis Bangunan & Jumlah Responden & Persentase $\%$ \\
\hline Petani Lapisan Atas & & \\
\hline Permanen & 3 & 75 \\
Semi permanen & 1 & 25 \\
Non permanen & - & 100 \\
\hline Sub-Jumlah & 4 & \\
\hline Petani Lapisan menengah & & 50 \\
\hline Permanen & 3 & 50 \\
Semi permanen & 3 & 100 \\
Non permanen & - & \\
\hline Sub-Jumlah & 6 & 40 \\
\hline Petani Lapisan bawah & & 60 \\
\hline Permanen & 2 & 100 \\
Semi permanen & 3 & 100 \\
Non permanen & - & \\
\hline Sub-Jumlah & 5 & \\
\hline Jumlah & 15 &
\end{tabular}

\section{Kesehatan Dan Pendidikan Anak}

Rata-rata responden ketika kesehatannya terganggu mereka semua lebih memilih berobat ke puskesmas ataupun ke dokter karena, semua responden memiliki kartu kesehatan berupa BPJS. Pendidikan anak-anak petani ada yang sudah tidak sekolah atau sudah lulus SMA, ada yang sementara sekolah di Perguruan Tinggi, dan kebanyakan masih bersekolah di tingkat SMA, SMP dan SD.

\section{Strategi Hidup Petani Padi Sawah di Desa Tumani Selatan}

\section{Petani Lapisan Atas}

Petani lapisan atas adalah petani pemilik penggarap dari 4 responden petani lapisan atas terdapat 1 responden yang mendapatkan lahan dari warisan orang tua, 1 reponden membeli lahan dari hasil ternak sapi dan 2 responden pada awalnya adalah penyewah lahan kemudian hasil yang di dapat di tabung di bank sehingga dapat membeli lahan sendiri. Petani pada lapisan ini cenderung menambah membeli atau menyewah lahan sawah pada petani yang lain agar lahan yang di usahakan lebih besar dan mendapatkan hasil yang lebih besar juga. Pada lapisan ini terdapat 1 petani yang memiliki lahan yang berjauhan kemudian salah satunya di jual untuk membeli lahan yang berdekatan karena menurut petani lahan yang berjahuan memakan waktu, tenaga dan biaya yang lebih besar di badingkan dengan lahan yang satu hamparan. Petani lapisan ini cenderung menyimpan hasil pendapatan mereka di bank, sehingga ketika ada petani yang akan menjual lahan mereka mengambil uang tabungan di bank untuk membeli lahan tersebut. Dan sebagian membeli sapi untuk di ternak, membuka usaha seperti pengumpul kelapa, dan membeli aset seperti mobil, traktor, motor dan barang berharga lainnya. 


\section{Petani Lapisan Menengah}

Pada petani lapisan ini hasil yang mereka dapat disimpan sendiri untuk kebutuhan keluarga, membeli sapi untuk di ternak, dan berternak ikan sehingga dapat menambah pendapatan dan dapat menambah lahan. Tetapi hanya satu petani yang dapat membeli dan menyewa lahan.

\section{Petani Lapisan Bawah}

Lapisan ini menerapkan strategi bertahan hidup dimana hasil yang mereka dapat hanya untuk kebutuhan hidup keluarga bahkan pendapatan mereka tidak cukup untuk memenuhi kebutuhan hidup mereka sehari hari. Untuk mencukupinya mereka meminjam uang kepada keluarga terdekat dan mereka melakukan pola hidup hemat dengan meminimalisir pengeluaran mereka baik kebutuhan sandang, dan pangan sehingga mereka tidak memiliki simpanan uang dari hasil bertani.

\section{KESIMPULAN DAN SARAN}

\section{Kesimpulan}

Berdasarkan hasil penelitian dan pengujian data yang telah dilakukan maka dapat disimpulkan, dari keempat faktor yakni tingkat Pendidikan, pengangguran, pertumbuhan PDRB, dan inflasi, faktor yang berpengaruh nyata terhadap tingkat kemiskinan di Provinsi Sulawesi Utara adalah tingkat pengangguran, sedangkan tingkat pendidikan, pertumbuhan PDRB, dan inflasi tidak berpengaruh nyata.

Hasil penelitian yang telah di lakukan menunjukkan bahwa strategi hidup petani lapisan atas menerapkan strategi akumulasi dan satu petani menerapkan strategi konsolidasi. Lapisan ini memiliki pendapatan yang melebihi kebutuhan sehingga dapat menembah lahan, membuka usaha, membeli sapi atau aset lainnya. Dan petani lapisan menengah menerapkan strategi akumulasi dimana mereka menabung sendiri untuk membeli sapi, budidaya ikan sehingga dapat menambah pendapatan dan menambah lahan. Sedangkan petani lapisan bawah menerapkan strategi bertahan hidup dimana mereka hanya fokus pada pemenuhan kebutuhan hidup sehari-hari sehingga mereka tidak dapat menabung.

\section{Saran}

Berdasarkan hasil penelitian ini, maka disarankan agar petani lapisan atas dan petani lapisan menengah mempertahankan strategi hidup yang telah di terapkannya selama ini. Dan untuk petani lapisan bawah perlu dukungan berupa kebijakan pemerintah yang berpihak pada mereka sehnigga mereka dapat meningkatkan pendapatan serta dapat menggunakan semua potensi yang ada untuk mendapatkan penghasilan tambahan.

\section{DAFTAR PUSTAKA}

Breman J (1992). Kerja dan Hidup sebagai buruh tanpa lahan dipesisir Jawa [Working ang living conditions of lanslessness labourers on the coastal are ofJava].

Khairani, N. (2010). Dampak Industrialisasi Terhadap Kehidupan Sosial Ekonomi Masyarakat Desa (Studi Kasus: Dampak PT. Inalum Terhadap Warga Desa Lalang Kecamatan Medang Deras).

Mardikantoro, H. B. (2013). Bahasa Jawa Sebagai Pengungkap Kearifan Lokal Masyarakat Samin Di Kabupaten Blora. Komunitas: International Journal Of Indonesian Society And Culture.

Scott, J. (1990). Perlawanan Kaum Tani. LP3ES. Jakarta.

Sugihardjo (2012). Strategi Bertahan dan Strategi Adaptasi Petani Terhadap Dunia Luar. Jakarta.

Sugiyono (2009). Metode Panalitian Kuantitatif, Kualitataif dan R\&B, Bandung Alfabeta. 